\title{
Cholinergic gating of hippocampal auditory evoked potentials in freely moving rats
}

Citation for published version (APA):

Klinkenberg, I., Sambeth, A., \& Blokland, A. (2013). Cholinergic gating of hippocampal auditory evoked potentials in freely moving rats. European Neuropsychopharmacology, 23(8), 988-997.

https://doi.org/10.1016/j.euroneuro.2012.08.014

Document status and date:

Published: 01/08/2013

DOI:

10.1016/j.euroneuro.2012.08.014

Document Version:

Publisher's PDF, also known as Version of record

Document license:

Taverne

\section{Please check the document version of this publication:}

- A submitted manuscript is the version of the article upon submission and before peer-review. There can be important differences between the submitted version and the official published version of record.

People interested in the research are advised to contact the author for the final version of the publication, or visit the DOI to the publisher's website.

- The final author version and the galley proof are versions of the publication after peer review.

- The final published version features the final layout of the paper including the volume, issue and page numbers.

Link to publication

\footnotetext{
General rights rights.

- You may freely distribute the URL identifying the publication in the public portal. please follow below link for the End User Agreement:

www.umlib.nl/taverne-license

Take down policy

If you believe that this document breaches copyright please contact us at:

repository@maastrichtuniversity.nl

providing details and we will investigate your claim.
}

Copyright and moral rights for the publications made accessible in the public portal are retained by the authors and/or other copyright owners and it is a condition of accessing publications that users recognise and abide by the legal requirements associated with these

- Users may download and print one copy of any publication from the public portal for the purpose of private study or research.

- You may not further distribute the material or use it for any profit-making activity or commercial gain

If the publication is distributed under the terms of Article $25 \mathrm{fa}$ of the Dutch Copyright Act, indicated by the "Taverne" license above, 


\title{
Cholinergic gating of hippocampal auditory evoked potentials in freely moving rats
}

\author{
Inge Klinkenberg*, Anke Sambeth, Arjan Blokland
}

\begin{abstract}
Faculty of Psychology and Neuroscience, Department of Neuropsychology and Psychopharmacology,
\end{abstract} Maastricht University, P.O. Box 616, 6200 MD Maastricht, The Netherlands

Received 15 March 2012; received in revised form 19 July 2012; accepted 20 August 2012

\section{KEYWORDS \\ Muscarinic; \\ Scopolamine; \\ Biperiden; \\ Donepezil; \\ Animal model; \\ Auditory evoked \\ potential}

\begin{abstract}
As perturbations in auditory filtering appear to be a candidate trait marker of schizophrenia, there has been considerable interest in the development of translational rat models to elucidate the underlying neural and neurochemical mechanisms involved in sensory gating. This is the first study to investigate the effects of the non-selective muscarinic antagonist scopolamine, the muscarinic M1 antagonist biperiden and the cholinesterase inhibitor donepezil (also in combination with scopolamine and biperiden) on auditory evoked potentials (AEPs) and sensory gating. In the saline condition, only the N50 peak displayed sensory gating. Scopolamine and biperiden both disrupted sensory gating by increasing N50 amplitude for the S2 click. Donepezil was able to fully reverse the effects of biperiden on N50 sensory gating, but had residual effects when combined with scopolamine; i.e., it enhanced sensory gating by increasing $\mathrm{N} 50$ amplitude of the $\mathrm{S} 1$ stimulus. Donepezil by itself improved sensory gating by enhancing N50 amplitude of S1, and reducing N50 amplitude of the S2 click. In conclusion, due to its relatively more selective effects biperiden is to be preferred over scopolamine as a means for pharmacologically inducing cholinergic impairments in auditory processing in healthy rats. Changes in auditory processing and sensory gating induced by cholinergic drugs may serve as a translational model for aging instead of schizophrenia.

(c) 2012 Elsevier B.V. and ECNP. All rights reserved.
\end{abstract}

\section{Introduction}

Sensory gating is thought to be essential for filtering out background information in order to allocate sufficient

\footnotetext{
Abbreviations: Amp, amplitude; Lat, latency; SG, sensory gating; Stim, Stimulus; Treat, Treatment; $\uparrow$, increased; $\downarrow$, decreased; n.s., not significant

*Corresponding author. Tel.: + 31043 3884217; fax: + 310433884560 .

E-mail address: inge.klinkenberg@maastrichtuniversity. $\mathrm{nl}$ (I. Klinkenberg).
}

processing capacity for salient and/or more important stimuli (Miyazato et al., 1999). In humans, intact sensory gating is defined as a reduction in amplitude of the P50 peak to the second of two identical, consecutive auditory clicks presented $500 \mathrm{~ms}$ apart (S1: first click or conditioning stimulus, S2: second click or test stimulus: Boutros et al., 2004; Brockhaus-Dumke et al., 2008; Oranje et al., 2006). Perturbations in auditory filtering, such as disrupted sensory gating of the P50 and N100 components, appear to be a candidate trait marker of schizophrenia (e.g., Cadenhead et al., 2000; Olincy et al., 2010; Simons et al., 2011; but see De Wilde et al., 2007). Hence, there has been considerable 
interest in the development of translational rodent models to elucidate the underlying neural and neurochemical mechanisms involved in sensory gating.

Auditory evoked potentials (AEPs) related to human components have been recorded in several rodent species, such as the mouse (e.g., Radek et al., 2006; Stevens et al., 1998; Stevens and Wear, 1997; Wildeboer and Stevens, 2008) and rat (e.g., de Bruin et al., 2001). However, there is some debate as to which component(s) in the rat AEP is the analogue of the human P50 (de Bruin et al., 2001). The human P50 peak displays gating at an inter-stimulus interval (ISI) of $500 \mathrm{~ms}$ and has been shown to be influenced by stimulus repetition; i.e., there is a gradual decrease in P50 amplitude with increasingly more paired-click trials, especially for S1 (e.g., Lamberti et al., 1993). Moreover, the P50 is dependent on the ISI; i.e., there is a progressive recovery of P50 amplitude of S2 with ISIs longer than $1 \mathrm{~s}$, thereby reducing sensory gating (e.g., Adler et al., 1982). The P50 is mediated by cholinergic signaling, as administration of the non-selective muscarinic antagonist scopolamine in human participants has been shown to reduce P50 amplitude or delay the occurrence of the P50 (Buchwald et al., 1991; Pekkonen et al., 2005). Therefore, these characteristics have been used as criteria for evaluating rat equivalents of the human P50. Several early positive and later-occurring negative peaks have been put forward, such as the P13 or $\mathrm{P} 17$, and the $\mathrm{N} 22, \mathrm{~N} 40$ or $\mathrm{N} 50$, respectively (Adler et al., 1986; Boutros et al., 1997; de Bruin et al., 2001; Miyazato et al., 1996). The source of these discrepancies in peak latencies between labs remains elusive, but can likely be attributed to methodological differences between studies.

Several pharmacological studies in rats have indicated a role for muscarinic neurotransmission in auditory processing. For instance, Miyazato et al. (1995) have reported a reduction in P13 amplitude after systemic injections of the muscarinic antagonist scopolamine at doses of 0.2 , 1 and $5 \mathrm{mg} / \mathrm{kg}$ (IP). Campbell et al. (1995) revealed that the amplitudes of P18 and N40 components to auditory stimuli were markedly decreased after systemic administration of scopolamine $(0.1-10 \mathrm{mg} / \mathrm{kg}, \mathrm{SC})$. These findings were extended by Sambeth et al. (2007) which showed that the amplitudes of N1 and N2 peaks became more negative but closer to baseline after scopolamine $(0.1 \mathrm{mg} / \mathrm{kg}$, IP), which was not reversed by concurrent administration of donepezil ( $3 \mathrm{mg} / \mathrm{kg}, \mathrm{IP})$. The authors concluded that this was due to a decrement in arousal induced by scopolamine. Two experiments have employed central infusion of scopolamine into discrete brain areas to determine effects on sensory gating. Teneud et al. (2000) showed that injections of the cholinergic agonist carbachol $(0.2,1$ or $5 \mathrm{mM}$ bilaterally) in the pedunculopontine nucleus reduced P13 amplitude in a doseand time-dependent manner, which was reversed by concurrent administration of scopolamine (20 mM bilaterally). Luntz-Leybman et al. (1992) demonstrated decrements in N40 amplitude in the CA3 layer of the hippocampus after cerebroventricular infusion of nicotinic antagonists, but not the muscarinic antagonist scopolamine.

It is currently unclear which muscarinic receptor subtype(s) might underlie the effects of scopolamine on auditory processing. Scopolamine is non-selective in terms of binding affinity and, depending on its dose, has the capability to block cholinergic neurotransmission at all muscarinic receptor subtypes M1-M5 (Bolden et al., 1992; Bymaster et al., 2003). As muscarinic receptors are found throughout the brain and body (Caulfield, 1993), interpretation of cognitive effects of this drug is complicated. Interestingly, the muscarinic M1 receptor subtype is predominantly located in brain regions thought to be important for learning and memory, such as the hippocampus. This brain region has been shown to be involved in the inhibition of responses to recurrent information, and unsurprisingly has also been strongly implicated in rat sensory gating (e.g., Bickford-Wimer et al., 1990; Bickford et al., 1993; Krause et al., 2003). Hence, blockade of the muscarinic M1 receptor subtype by selective $M 1$ antagonists might induce more selective effects compared to scopolamine. In addition, muscarinic M1 antagonists might be useful as a translational model for aberrant auditory processing seen in neuropsychiatric populations such as in schizophrenia.

Therefore, the present study investigated the effects of the non-selective muscarinic antagonist scopolamine, the more selective muscarinic $M 1$ antagonist biperiden and the cholinesterase inhibitor donepezil (also in combination with scopolamine and biperiden) on AEPs and sensory gating. Based on previous studies we expected that after scopolamine, all AEP components would show reduced amplitudes and/or delayed latencies. Since biperiden is a relative specific muscarinic M1 antagonist we anticipated a more selective effect on auditory processing. Thus, not all AEP peaks will be affected after biperiden. Effects of scopolamine and biperiden would be reversible by concurrent administration of donepezil.

\section{Experimental procedures}

\subsection{Subjects}

All experimental procedures were approved by the local ethical committee for animal experiments at Maastricht University and met governmental guidelines. Fourteen 3-month old male Wistar rats (Harlan, NL) served as subjects in this study. They were housed in pairs in standard type III Makrolon ${ }^{T M}$ cages on sawdust bedding in an air-conditioned room $\left(21^{\circ} \mathrm{C}, 45-55 \%\right.$ humidity) under a reversed light/dark cycle (lights on from $5 \mathrm{PM}$ to $5 \mathrm{AM}$ ). After surgery, animals were singly housed in cages with a flat top which are normally used for individually ventilated conditions. This was done in order to ensure that the rats would not damage their electrodes. Rats were housed in the room in which they were tested. All testing was performed between 9 AM and 5 PM (i.e., during the dark period). This ensured that the animals were in their active phase and minimized the possibility that they would fall asleep during a test session, which was always passive and hence did not require a behavioral response. The animals had unlimited access to food and water.

\subsection{Surgical procedures and EEG recording}

Rats were injected subcutaneously with the analgesic drug Temgesic $(0.1 \mathrm{mg} / \mathrm{kg})$. Next, rats were anesthetized with inhalation of isoflurane and placed into a stereotaxic frame using custom-made, blunted ear bars which protected the middle ear from injury. After making a vertical incision and exposing the skull, lidocane was used as a local anesthetic before removing the periosteum. Subsequently, the bregma intersection was used as a landmark in order to determine the electrode position corresponding to the dorsal hippocampus (anterior-posterior -2.8 , medial-lateral -1.8 , 
dorsal-ventral -2.6). Small holes were drilled in the skull to allow the insertion of electrodes. The reference and ground electrodes were placed in the cerebellum. The plug we used for EEG recording was a Cinch ${ }^{\circledR}$ Dura-Con D connector (screw mount flange) with 9 contacts to which $0.28 \mathrm{~mm}$ diameter polyimide covered stainless steel wires were soldered (taken from PlasticsOne ${ }^{\circledR} 3$ channel electrode units). The polyimide insulation was removed from the most distal part of the electrode wire in order to record field potentials. In order to fixate the electrode on the skull surface three screws and dental acrylic cement were used. The animals were allowed three weeks to recover from surgery.

During the next two weeks, the rats were habituated to the experimental procedures - i.e., the test chamber, the EEG acquisition system, the paired-click task and drug administration - before actual drug testing took place. During those habituation sessions the EEG signal was visually monitored for any abnormalities. EEG was always recorded from unrestrained, alert rats. The EEG was amplified, filtered between 1 and $133 \mathrm{~Hz}$ and sampled at $1000 \mathrm{~Hz}$. The animals underwent a total of nine testing sessions; we tested saline, scopolamine and biperiden twice, whereas donepezil, scopolamine-donepezil and biperiden-donepezil were tested once. Each session started with the injection of the drugs. Thirty minutes later, the rats were attached to the EEG equipment and EEG was visually checked. Two test chambers with EEG equipment were at our disposal; therefore two rats could be tested simultaneously.

\subsection{Paired-click task}

The paired-click task was used as an electrophysiological technique to assess sensory gating mechanisms (Adler et al., 1982). Two identical $2500 \mathrm{~Hz}$ clicks (S1 and S2) were binaurally presented via loudspeakers. The duration of each click was $4 \mathrm{~ms}$ with a sound intensity of $80 \mathrm{~dB}(\mathrm{~A})$. A short inter-stimulus interval (ISI) of $500 \mathrm{~ms}$ was used. This ISI has been shown to provide maximum differentiation between the sensory gating capacities of healthy participants and schizophrenia patients (Nagamoto et al., 1989; Oranje et al., 2006). Moreover, rat studies have shown that using inter-stimulus intervals between 200 and 600 ms consistently yield sensory gating effects (Adler et al., 1986; de Bruin et al., 2001). The pairs were presented in a random intertrial interval of 6-10 s, in order to allow neuronal recovery (Zouridakis and Boutros, 1992). During each session 70 pairs of clicks were presented. No behavioral measures were recorded during this task.

\subsection{Drug administration}

Please refer to Table 1 for information on drug administration. Doses and pretreatment time were chosen based on previous scopolamine and biperiden data (Klinkenberg and Blokland, 2011;
Sambeth et al., 2007). The order of doses was semi-randomized over testing days. All animals received the same treatment condition in a test session. Saline, scopolamine and biperiden were tested twice on separate testing days, whereas donepezil and the combination treatments were tested only once. Drug solutions were prepared freshly each day prior to testing. Test administrators were not blinded for the treatment conditions, as they could not influence the data (i.e., only EEG recording, no behavioral data). To ensure sufficient wash-out of the drug, testing days were always separated by at least one drug-free day (for half-lives please refer to: Legault et al., 2004; Yokogawa et al., 1992).

\subsection{EEG data analysis}

All EEG data was analyzed with BrainVision Analyzer version 2.0, professional edition (Copyright ${ }^{\circledR}$ Brain Products $\mathrm{GmbH}$ 1998-2008). Before data analysis, the EEG data were visually inspected offline, to check for artefacts. The EEG signal was filtered offline with a high pass filter set at $1 \mathrm{~Hz}$ ( $12 \mathrm{~dB}$ slope) and a low pass filter set at $30 \mathrm{~Hz}$ (12 dB slope). AEP epochs were set from $100 \mathrm{~ms}$ prior to stimulus onset to $500 \mathrm{~ms}$ after onset. The interval from -100 to 0 was taken as baseline. After manual artefact rejection, separate averages were calculated for each rat, stimulus, and treatment condition. Based on the grand averages we determined the position of early auditory peaks relative to baseline for S1 and S2. Peak amplitudes and latencies were calculated based on when the peak was reached. We found a positive peak around $32 \mathrm{~ms}$, a negative deflection at $50 \mathrm{~ms}$, and again a positive peak around $70 \mathrm{~ms}$ poststimulus. These have been dubbed P32, N50 and P70, respectively. Please see Table 2 for the time windows chosen for peak detection.

\subsection{Statistics}

In some cases a particular peak was missing in the AEP data. In order to be able to do repeated measures ANOVAs, we replaced missing values with the average of rats that did show that peak. In the case of two testing days (i.e., for saline, scopolamine and biperiden) the data were averaged before statistical analysis. All data were analyzed using SPSS.

In order to determine whether there was intact sensory gating, AEP data of the saline condition were analyzed with repeated measures ANOVAs with Stimulus (2 levels: S1 and S2) as within-subject variable. Next, we wanted to assess the effects of scopolamine and donepezil on sensory gating. Therefore we performed several repeated measures ANOVAs with Drug (4 levels: saline, scopolamine, donepezil, and scopolamine-donepezil) and Stimulus (2 levels: S1 and S2) as withinsubject variables. Finally, we wanted to assess the effects of biperiden and donepezil on sensory gating. Therefore we did several repeated measures ANOVAs with Drug (4 levels: saline, biperiden, donepezil,

Table 1 Drug administration.

\begin{tabular}{|c|c|c|c|c|c|c|}
\hline Drug & Supplier & Vehicle & $\begin{array}{l}\text { Pretreatment } \\
\text { time (min) }\end{array}$ & $\begin{array}{l}\text { Administration } \\
\text { route }\end{array}$ & $\begin{array}{l}\text { Volume } \\
(\mathrm{mL} / \mathrm{kg})\end{array}$ & $\begin{array}{l}\text { Dose conditions } \\
\text { (mg/kg) }\end{array}$ \\
\hline $\begin{array}{l}\text { Scopolamine } \\
\text { hydrobromide } \\
\text { trihydrate } 99 \%\end{array}$ & Acros Organics & Isotonic saline & 30 & I.P. & 1 & 0.1 \\
\hline $\begin{array}{l}\text { Biperiden lactate } \\
\left(\text { Akineton }{ }^{\circledR}\right)\end{array}$ & $\begin{array}{l}\text { Laboratorio } \\
\text { Farmaceutico S.I.T. }\end{array}$ & $\begin{array}{l}\text { Milli-Q } \\
\text { purified water }\end{array}$ & 30 & I.P. & 1 & 1 \\
\hline $\begin{array}{l}\text { Donepezil } \\
\left(\text { Aricept }^{\mathbb{R}}\right)\end{array}$ & Apin chemicals & $\begin{array}{l}\text { Milli-Q } \\
\text { purified water }\end{array}$ & 30 & P.O. & 2 & 3 \\
\hline
\end{tabular}


Table 2 Time windows (in ms) used for analysis of the AEP data.

\begin{tabular}{lllllll}
\hline Peaks & \multicolumn{2}{l}{ Drug condition } & & & \\
\cline { 2 - 6 } & Saline & Scopolamine & Biperiden & Donepezil & Scopolamine-Donepezil & Biperiden-Donepezil \\
\hline P32 & $10-50$ & $10-50$ & $10-50$ & $10-50$ & $10-40$ & $10-50$ \\
N50 & $20-70$ & $20-70$ & $30-80$ & $30-80$ & $30-80$ & $20-70$ \\
P70 & $50-100$ & $60-100$ & $50-110$ & $50-100$ & $50-100$ & $50-100$ \\
\hline
\end{tabular}

and biperiden-donepezil) and Stimulus (2 levels: S1 and S2) as withinsubject variables.

All analyses were done separately for amplitude and latency, and for each of the AEP components (i.e., P32, N50 and P70). Significant interactions between Treatment and Stimulus would be reflective of a Treatment effect on sensory gating. In this case we performed additional ANOVAs split for each level of Stimulus (i.e., S1 versus S2) in order to examine simple effects. For reasons of brevity, we decided to not discuss main effects of Stimulus in the $4 \times 2$ Treatment analyses, as these effects were already covered by analyses on the saline data with respect to the effect of Stimulus. Post-hoc analyses were performed with a Least Significant Difference (LSD) test; we decided to only focus on treatment effects relative to the saline condition.

\section{Results}

Five rats lost their electrodes prematurely and/or did not have a clear EEG signal. These were eliminated from the final analysis, leaving a total of 9 rats.

\subsection{Stimulus effects in the saline condition on AEPs and sensory gating}

Figure 1 shows an overview of the effects of scopolamine, biperiden, donepezil and the combined treatments on hippocampal processing of auditory stimuli. In the analyses of the saline data, there was no main effect of Stimulus on P32 or P70 amplitude (no main effect of Stimulus; Fs $<2.59$, n.s.). N50 amplitude was larger for S1 compared to S2 (main effect of Stimulus; $F(1,8)=5.78, P<0.05)$. As for the latency data, there was no main effect of Stimulus on P32 or P70 latency (no main effect of Stimulus; Fs $<2.78$, n.s.). N50 latency was slowed for S1 compared to S2 (main effect of Stimulus; $F(1,8)=6.88, P<0.05)$.

\subsection{Effects of scopolamine, donepezil and the combination treatment on AEPs and sensory gating}

The treatment analyses of P32 or P70 amplitude did not yield any relevant effects $(F s<2.98$, n.s.). An overview of the effects of scopolamine, biperiden, donepezil and the combination treatments on N50 amplitude is shown in Figure 2. The effect of Treatment on N50 amplitude varied per level of Stimulus (Treatment $\times$ Stimulus interaction effect; $F(3,24)=11.88, P<0.001)$. Therefore we performed simple effects analysis per level of Stimulus. In the analysis of S1, N50 amplitude was shown to be different between treatment conditions (main effect of Treatment; $F(3,24)=$ 5.77, $P<0.01$ ); post-hoc analysis indicated that the N50 amplitude of the S1 stimulus was larger after donepezil
$(P<0.01)$ and scopolamine-donepezil $(P<0.01)$ compared to the saline condition. In the analysis of S2, N50 amplitude was also different between treatment conditions (main effect of Treatment; $F(3,24)=5.26 P<0.01$ ); post-hoc analysis indicated that the $\mathrm{N} 50$ amplitude of the S2 stimulus was larger after scopolamine $(P<0.001)$ and smaller after donepezil $(P<0.01)$ compared to saline.

The effect of Treatment on P32 latency did not vary per level of Stimulus (no Treatment $\times$ Stimulus interaction effect; $F(3,24)=2.39$, n.s.). P32 latency was shown to be different between treatment conditions (main effect of Treatment; $F(3,24)=4.40, P<0.05)$; post-hoc analysis indicated that P32 latency was shorter after scopolamine compared to saline $(P<0.05)$. In the analysis of N50 latency, the effect of Treatment varied per level of Stimulus (Treatment $\times$ Stimulus interaction effect; $F(3,24)=4.49, P<0.05)$. Therefore we performed simple effects analyses per level of Stimulus. In the analysis of $\mathrm{S} 1$, there was no main effect of Treatment on N50 latency $(F(3,24)=1.98$, n.s. $)$. In the analysis of S2, N50 latency was shown to be different between treatment conditions (main effect of Treatment; $F(3,24)=3.58 P<0.05$ ); posthoc analysis indicated that the N50 latency of the S2 stimulus was larger after scopolamine compared to saline $(P<0.05)$. The effect of Treatment on P70 latency did not differ per level of Stimulus (no Treatment $\times$ Stimulus interaction effect; $F(3,24)=1.09$, n.s.). P70 latency was shown to be different between treatment conditions (main effect of Treatment; $F(3,24)=5.37 P<0.01$ ); post-hoc analysis indicated that P70 latency was larger after scopolamine $(P<0.05)$ and after scopolamine-donepezil $(P<0.01)$ compared to saline.

\subsection{Effects of biperiden, donepezil and the combination treatment on AEPs and sensory gating}

The effect of Treatment on P32 amplitude did not differ per level of Stimulus (no Treatment $\times$ Stimulus interaction effect; $F(3,24)=0.27$, n.s.). There was a main effect of Treatment $(F(3,24)=4.87, P<0.01)$; however, post-hoc analysis did not yield any significant effects. In the analysis of N50 amplitude, the effect of Treatment varied per level of Stimulus (Treatment $\times$ Stimulus interaction effect; $F(3,24)=9.90, P<0.001)$. Therefore we performed simple effects analysis per level of Stimulus. In the analysis of S1, N50 amplitude was shown to be different between treatment conditions (main effect of Treatment; post-hoc analysis indicated that the N50 amplitude of the S1 stimulus was larger after donepezil compared to saline $(P<0.01))$. In the analysis of S2, N50 amplitude was shown to be different between treatment conditions (main effect of Treatment; $F(3,24)=13.44 P<0.001$ ); post-hoc analysis indicated that the $\mathrm{N} 50$ amplitude of the S2 stimulus was 

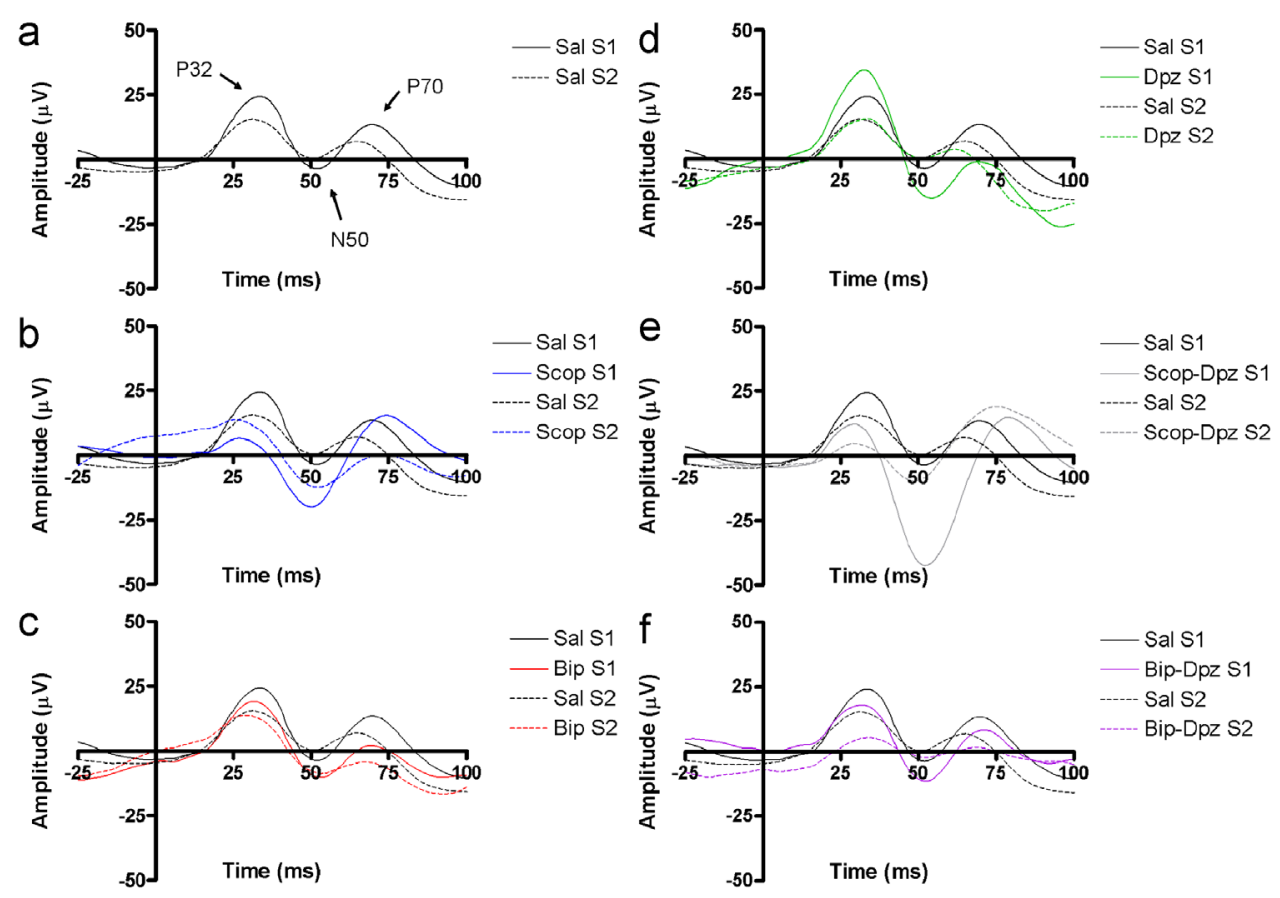

Figure 1 AEPs showing the effects of the treatment conditions on hippocampal processing of auditory stimuli (grand averages). Amplitude effects: (a) After saline, N50 amplitude was larger for the S1 compared to the S2 stimulus. (b) There was a Treatment $\times$ Stimulus interaction in the analysis of the N50 amplitude data. N50 amplitude of the S2 stimulus was increased after scopolamine, which reflects a reduction in sensory gating. (c) Biperiden increased the N50 amplitude of the S2 stimulus, suggestive of a reduction in sensory gating. (d) After donepezil, N50 amplitude of the $\mathrm{S} 1$ stimulus was increased, whereas N50 amplitude of the S2 stimulus was reduced. This finding would suggest that donepezil increases sensory gating at the N50 peak. (e) Scopolaminedonepezil induced an increase in N50 amplitude of the S1 stimulus, which reflects an increase in sensory gating. (f) Biperidendonepezil did not affect auditory processing. Latency effects: (a) After saline, N50 latency was larger for the S1 compared to the S2 stimulus. (b) After scopolamine, the occurrence of the P32 peak was earlier compared to the saline condition. Scopolamine also increased the N50 latency of the S2 stimulus and P70 latency of both stimulus types. (c- $\mathrm{f}$ ) Biperiden, donepezil, scopolaminedonepezil and biperiden-donepezil did not affect peak latencies.

larger after biperiden $(P<0.001)$ and smaller after donepezil $(P<0.05)$ compared to saline. The treatment analysis of P70 amplitude, P32 latency or P70 latency did not yield any relevant interaction or main effects $(F s<1.72$, n.s.). In the analysis of $\mathrm{N} 50$ latency there was a main effect of Treatment $(F(3,24)=3.30, P<0.05)$; however, post-hoc analysis did not yield any significant effects.

\section{Discussion}

The goal of the current study was to assess the effects of the muscarinic antagonists scopolamine and biperiden, and the cholinesterase inhibitor donepezil on auditory processing and sensory gating. In Table 3 an overview is given of the effects of our treatment conditions.

\subsection{Summary of results}

In the present study we saw a clear sensory gating effect at the N50 component in the saline condition. Specifically, there was a relative decrease of N50 amplitude to the second click (S2) compared with the first (S1), which is a measure of sensory gating. The P32 and P70 peaks did not show any sensory gating effects. Scopolamine disrupted sensory gating of the N50 component (i.e., there was a
Treatment $\times$ Stimulus interaction). A closer look at the data revealed that an increase in $\mathrm{N} 50$ amplitude of the S2 stimulus relative to the saline condition was responsible for this effect. Scopolamine combined with donepezil enhanced sensory gating by increasing the N50 amplitude of S1. N50 amplitude of the S2 stimulus was unchanged relative to saline after scopolamine-donepezil. The former finding is likely due to an underlying effect of donepezil, also given the fact that donepezil by itself (i.e., without add-on treatment with a muscarinic antagonist) improved sensory gating by enhancing N50 amplitude to S1, and by decreasing N50 amplitude to the S2 stimulus. The lack of effect on the $\$ 2$ stimulus after the combination treatment is likely reflective of a reversal of the scopolamine-induced increment in N50 amplitude of the S2 stimulus by donepezil. Scopolamine did not affect P32 or P70 amplitude.

As expected, biperiden had much more selective effects on auditory processing. It impaired sensory gating by increasing the $\mathrm{N} 50$ amplitude of the $\mathrm{S} 2$ stimulus (i.e., we found a Treatment $\times$ Stimulus interaction), which was fully reversed by concurrent administration of donepezil. The biperiden-donepezil combination treatment also did not influence N50 amplitude of S1. Biperiden did not influence P32 or P70 amplitude. There were also several latency effects. In the saline condition, N50 latency was faster for 


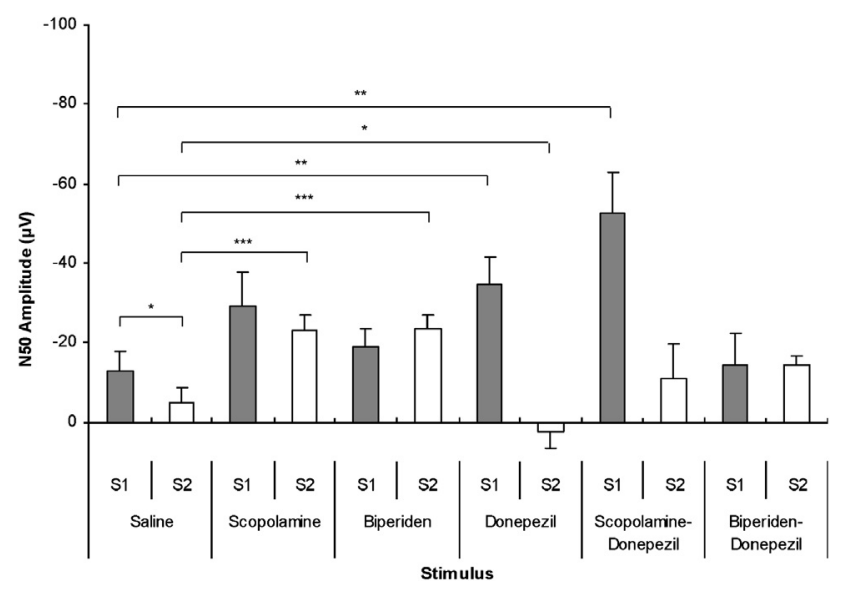

Figure 2 Effects of the treatment and stimulus conditions on N50 amplitude (means+SEMs). Both scopolamine and biperiden disrupted sensory gating by increasing N50 amplitude of the S2 stimulus. Scopolamine-donepezil increased N50 amplitude of S1. This likely reflects an underlying effect of donepezil, also given the fact that donepezil by itself improved sensory gating by enhancing $\mathrm{N} 50$ amplitude of $\mathrm{S} 1$, and reducing $\mathrm{N} 50$ amplitude of the S2 stimulus. Moreover, after scopolaminedonepezil N50 amplitude of the S2 stimulus was similar to the saline condition, reflecting a reversal of the effects of scopolamine by donepezil. After the biperiden-donepezil combination treatment, N50 amplitude was statistically similar to the saline condition, reflecting a reversal of the effects of biperiden by donepezil.

S2 relative to the S1 stimulus. After scopolamine, P32 latency was decreased, which was reversed by concurrent administration of donepezil. Scopolamine also slowed N50 latency of the S2 stimulus relative to the saline condition, which was reversed by concurrent administration of donepezil. Lastly, P70 latency was increased after scopolamine. This was also the case for the combination treatment, which implies that donepezil was unable to reverse the effects of scopolamine on P70 latency. Biperiden did not influence peak latencies.

In sum, scopolamine induced widespread effects on auditory processing besides affecting sensory gating at the N50 component. Donepezil was also not able to completely counteract all these effects. In contrast, biperiden only influenced sensory gating at the N50 peak, which was fully reversed by concurrent donepezil administration. These findings are in line with the binding affinities of scopolamine and biperiden for muscarinic receptors (i.e., non-selective versus relatively selective for the muscarinic M1 receptor subtype, Bolden et al., 1992; Katayama et al., 1990). Furthermore, our results strongly suggest that biperiden is to be preferred over scopolamine as a means for pharmacologically inducing cholinergic impairments in auditory processing in healthy rats.

\subsection{Effects of cholinergic drugs on AEPs in rats}

The findings of the current study are in contrast with those reported in the literature. Several articles have demonstrated a reduction in peak amplitude of early positive, but not negative components after scopolamine (Miyazato et al., 1995;
Teneud et al., 2000). ${ }^{1}$ However, Campbell et al. (1995) found that scopolamine induced a decrement in amplitudes of both P18 and N40 peaks, which was more pronounced for the latter than the former component. Moreover, LuntzLeybman et al. (1992) reported no effect of scopolamine on N40 gating. There are several methodological differences which might explain the discrepancies in findings between these experiments.

Firstly, the current study used Wistar rats whereas others used Sprague-Dawley rats (Campbell et al., 1995; LuntzLeybman et al., 1992; Miyazato et al., 1995; Teneud et al., 2000). Strain differences may explain some differences between studies (e.g., Adler et al., 1986), but these appear to be minimal (e.g., Borg, 1982; Potier et al., 1993). However, even rats that belong to the same strain but have been obtained from different suppliers can show discrepancies in AEP components within the same experiment (e.g., Adler et al., 1986). Of note, no strain differences in CA1 neuronal response to applications of the cholinergic agonist carbachol have been reported (Potier et al., 1993). Differences between Wistar and Sprague-Dawley rats in terms of auditory thresholds are also minimal (Borg, 1982).

Secondly, we recorded EEG from freely moving rats receiving systemic injections of cholinergic drugs, whereas Luntz-Leybman et al. (1992) used recordings from anesthetized animals. Anesthetic drugs are likely to interact with the effects of muscarinic antagonists on auditory processing. In addition, it has been shown previously that motor behavior increases acetylcholine levels in the hippocampus (Dudar et al., 1979). Hence, hippocampal AEP recordings in freely moving animals might differ from those of immobile, anesthetized animals in terms of baseline cholinergic tone and might therefore also respond differently to disruption by anti-muscarinic agents. Moreover, both Luntz-Leybman et al. (1992) and Miyazato et al. (1995) have used central infusions of scopolamine-i.e., in the lateral ventricle and in the pedunculopontine nucleus, respectively. Systemic and central administration of drugs is not fully comparable in terms of effects on behavior and EEG. Namely, systemic injections also induce peripheral side-effects, caused by binding of a drug outside of the central nervous system (Klinkenberg and Blokland, 2010).

Thirdly, different recording sites were used for our study and those previously reported in the literature (Campbell et al., 1995; Luntz-Leybman et al., 1992; Miyazato et al., 1995; Teneud et al., 2000). We measured EEG in the dorsal hippocampus, whereas previous studies have used area CA3 in the ventral hippocampus (Luntz-Leybman et al., 1992) or the vertex (Campbell et al., 1995; Miyazato et al., 1995; Teneud et al., 2000) as recording sites. These brain areas comprise distinct parts of the cholinergic system (Mesulam et al., 1983; Woolf and Butcher, 1986; Woolf et al., 1984) and might therefore be differentially sensitive to effects of (anti-)muscarinic drugs on auditory processing due to regional diversity in cholinergic innervation.

In addition, within the hippocampus the muscarinic M1 receptor has been shown to be enriched in dorsal versus

\footnotetext{
${ }^{1}$ The articles of Miyazato et al. (1995) and Teneud et al. (2000) have measured AEPs in relation to sleep stages and the reticular activating system. Hence, the background of these studies is markedly different to ours.
} 
Table 3 Treatment effects on AEPs and sensory gating. In case of the saline condition, a comparison is made between S1 and S2. Drug effects are always compared to the saline condition. Treat $\times$ Stim reflects an interaction effect, which implies that a particular drug influences sensory gating. In this case, drug effects are presented as simple effects (i.e., per level of Stimulus).

\begin{tabular}{|c|c|c|c|c|c|c|}
\hline \multirow[t]{3}{*}{ Treatment conditions } & \multicolumn{6}{|l|}{ Peaks } \\
\hline & \multicolumn{2}{|l|}{ P32 } & \multicolumn{2}{|l|}{ N50 } & \multicolumn{2}{|l|}{ P70 } \\
\hline & Amplitude & Latency & Amplitude & Latency & Amplitude & Latency \\
\hline Saline & n.s. & n.s. & $\mathrm{S} 1>\mathrm{S} 2(P<0.05)$ & $\mathrm{S} 1>\mathrm{S} 2(P<0.05)$ & n.s. & n.s. \\
\hline Scopolamine & n.s. & $\downarrow(P<0.05)$ & $\begin{array}{l}\text { SG } \downarrow(\text { Treat } \times \text { Stim }) \\
\text { S1: n.s. } \\
\text { S2: } \uparrow(P<0.001)\end{array}$ & $\begin{array}{l}(\text { Treat } \times \text { Stim }) \\
\text { S1: n.s. } \\
\text { S2: } \uparrow(P<0.05)\end{array}$ & n.s. & $\uparrow(P<0.05)$ \\
\hline Scopolamine-donepezil & n.s. & n.s. & $\begin{array}{l}\text { SG } \uparrow(\text { Treat } \times \text { Stim }) \\
\text { S1: } \uparrow(P<0.01) \\
\text { S2: n.s. }\end{array}$ & n.s. & n.s. & $\uparrow(P<0.01)$ \\
\hline Biperiden & n.s. & n.s. & $\begin{array}{l}\text { SG } \downarrow(\text { Treat } \times \text { Stim }) \\
\text { S1: n.s. } \\
\text { S2: } \uparrow(P<0.001)\end{array}$ & n.s. & n.s. & n.s. \\
\hline Biperiden-donepezil & n.s. & n.s. & n.s. & n.s. & n.s. & n.s. \\
\hline Donepezil & n.s. & n.s. & $\begin{array}{l}\text { SG } \uparrow(\text { Treat } \times \text { Stim }) \\
\text { S1: } \uparrow(P \mathrm{~S}<0.01) \\
\text { S2: } \downarrow(P \mathrm{~S}<0.05)\end{array}$ & n.s. & n.s. & n.s. \\
\hline
\end{tabular}

ventral sites (i.e., area CA1 compared to CA3: Levey et al., 1995). The fact that in the current study we have used a muscarinic M1 receptor antagonist and have measured AEPs in a brain region especially dense in muscarinic $M 1$ receptors might have contributed to the discrepancies between the current study and those reported in the literature (LuntzLeybman et al., 1992). That is, blockade of muscarinic M2-M5 receptors might be partly responsible for the effects of scopolamine on auditory processing in previous studies. This is also the reason why a more selective muscarinic antagonist such as biperiden is preferable over scopolamine in order to be able to attribute changes in AEP components to blockade of particular muscarinic receptor subtype(s).

Interestingly, the study by Sambeth et al. (2007) was comparable to the current one in terms of experimental setup. They also recorded AEPs from the dorsal hippocampus in freely moving Wistar rats and used the same doses for scopolamine and donepezil. Scopolamine $(0.1 \mathrm{mg} / \mathrm{kg}, \mathrm{IP})$ made the $\mathrm{N} 1$ amplitude more negative, which was in line with our own findings. However, the authors concluded that the N1 became closer to baseline after scopolamine. Concurrent administration of donepezil ( $3 \mathrm{mg} / \mathrm{kg}$, IP) failed to reverse these effects.

Of note, acetylcholinesterase inhibitors such as donepezil enhance cholinergic signaling non-selectively by preventing the breakdown of acetylcholine by cholinesterase enzymes (Jann et al., 2002). Thus, relatively higher amounts of acetylcholine are present in the synaptic cleft to bind to cholinergic receptors, regardless of receptor subtype. Hence, the enhancement of sensory gating by donepezil could be due to binding of acetylcholine to muscarinic receptors, nicotinic receptors, or both. For instance, rodent studies have shown that nicotinic agonists improve sensory gating by increasing the amplitude of the S1 click, and/or by decreasing the amplitude of the S2 click (Radek et al., 2006; Stevens et al., 1998; Stevens and Wear, 1997; Wildeboer and Stevens, 2008), which is in line with our current findings after donepezil. Specifically, it seems that stimulation of $\alpha 4 \beta 2$ nicotinic receptors is responsible for the former (Radek et al., 2006; Wildeboer and Stevens, 2008), whereas stimulation of $\alpha 7$ nicotinic receptors underlies the latter effect (Stevens et al., 1998). Thus, our finding of enhanced sensory gating after administration of donepezil (i.e., increase in N50 amplitude of S1 and decrease in N50 amplitude of S2) might be due to activation of $\alpha 4 \beta 2$ and $\alpha 7$ nicotinic receptors, respectively.

\subsection{Cholinergic drugs as a model for auditory processing and sensory gating deficits in schizophrenia}

In sum, data on the effects of cholinergic drugs on auditory processing and sensory gating in rats and healthy participants are not very straightforward, which can be partly explained by species and/or methodological differences between experiments. Overall, muscarinic antagonists and cholinesterase inhibitors appear to mainly affect early positive and negative peaks in the AEP. Moreover, they influence sensory gating in the rat, but not in healthy human participants. However, the question remains whether cholinergic drugs would be useful as a translational model for aberrant auditory processing in schizophrenia. Although impairments in sensory gating are not reported consistently in schizophrenia (e.g., Jin et al., 1997, 
1998; Kathmann and Engel, 1990), the main finding is that suppression deficits can be attributed to a reduction of the P50 and N100 response to S1 (e.g., Brockhaus-Dumke et al., 2008; but see Jin et al., 1997; Patterson et al., 2000). These reports are hard to relate to our own results of disrupted sensory gating due to increased N50 amplitude of the S2 stimulus after scopolamine and biperiden.

However, the validity of auditory perturbations as an endophenotype for schizophrenia has been questioned. For instance, there are indications that auditory processing deficits might be a state instead of a trait marker (e.g., Bramon et al., 2004; Nagamoto et al., 1996). In addition, the specificity of auditory processing deficits in schizophrenia is not very high. In aging and age-related disorders such as mild cognitive impairment and Alzheimer's disease, an increase in amplitudes of early AEP components (Golob et al., 2001; Irimajiri et al., 2005) and reduced sensory gating due to an increase in P50 amplitude of the S2 click has been reported (Cancelli et al., 2006; Jessen et al., 2001; Thomas et al., 2010; but see Buchwald et al., 1989; Fein et al., 1994). These findings are thus much more in line with our current results of increased N50 amplitudes induced by scopolamine and biperiden. Therefore, we would like to suggest that changes in auditory processing and sensory gating induced by cholinergic drugs may serve as a translational model for aging instead of schizophrenia. For future research, it would be interesting to determine possible dissociations between drugs that target different muscarinic receptor subtypes in terms of their effects on auditory processing and the relation with cognitive functions. The present study suggests that this may be relevant for aging and/or Alzheimer's dementia but probably not for schizophrenia.

\section{Role of funding source}

Funding for this study was provided by Grant 08554 from the Dutch Alzheimer Society (ISAO). The ISAO had no further role in the study design; in the collection, analysis and interpretation of data; in the writing of the report; and in the decision to submit to European Neuropsychopharmacology for publication.

\section{Contributors}

Inge Klinkenberg was involved in the data acquisition, performed the statistical analysis, and wrote the manuscript. Anke Sambeth designed the study, wrote the research protocol, was involved in the data acquisition and statistical analysis, and reviewed the manuscript. Arjan Blokland also gave feedback on first drafts of the manuscript. All authors have contributed to and have approved of the final manuscript.

\section{Conflict of interest}

The authors declare that, except for income received from their primary employer, no financial support or compensation has been received from any individual or corporate entity over the past three years for research or professional service. There are no personal, financial or other holdings that could be perceived as constituting a potential conflict of interest.

\section{Acknowledgements}

We would like to thank Jasmijn Kromhout for her assistance with the EEG recording.

\section{References}

Adler, L.E., Pachtman, E., Franks, R.D., Pecevich, M., Waldo, M.C., Freedman, R., 1982. Neurophysiological evidence for a defect in neuronal mechanisms involved in sensory gating in schizophrenia. Biol. Psychiatry 17, 639-654.

Adler, L.E., Rose, G., Freedman, R., 1986. Neurophysiological studies of sensory gating in rats: effects of amphetamine, phencyclidine, and haloperidol. Biol. Psychiatry 21, 787-798.

Bickford-Wimer, P.C., Nagamoto, H., Johnson, R., Adler, L.E., Egan, M., Rose, G.M., Freedman, R., 1990. Auditory sensory gating in hippocampal neurons: a model system in the rat. Biol. Psychiat. 27, 183-192.

Bickford, P.C., Luntz-Leybman, V., Freedman, R., 1993. Auditory sensory gating in the rat hippocampus: modulation by brainstem activity. Brain Res. 607, 33-38.

Bolden, C., Cusack, B., Richelson, E., 1992. Antagonism by antimuscarinic and neuroleptic compounds at the five cloned human muscarinic cholinergic receptors expressed in Chinese hamster ovary cells. J. Pharmacol. Exp. Ther. 260, 576-580.

Borg, E., 1982. Auditory thresholds in rats of different age and strain. A behavioral and electrophysiological study. Hear. Res. 8, 101-115.

Boutros, N.N., Bonnet, K.A., Millana, R., Liu, J., 1997. A parametric study of the $\mathrm{N} 40$ auditory evoked response in rats. Biol. Psychiatry 42, 1051-1059.

Boutros, N.N., Korzyukov, O., Jansen, B., Feingold, A., Bell, M., 2004. Sensory gating deficits during the mid-latency phase of information processing in medicated schizophrenia patients. Psychiatr. Res. 126, 203-215.

Bramon, E., Rabe-Hesketh, S., Sham, P., Murray, R.M., Frangou, S., 2004. Meta-analysis of the P300 and P50 waveforms in schizophrenia. Schizophr. Res. 70, 315-329.

Brockhaus-Dumke, A., Schultze-Lutter, F., Mueller, R., Tendolkar, I., Bechdolf, A., Pukrop, R., Klosterkoetter, J., Ruhrmann, S., 2008. Sensory gating in schizophrenia: P50 and N100 gating in antipsychotic-free subjects at risk, first-episode, and chronic patients. Biol. Psychiatry 64, 376-384.

Buchwald, J.S., Erwin, R.J., Read, S., Van Lancker, D., Cummings, J.L., 1989. Midlatency auditory evoked responses: differential abnormality of P1 in Alzheimer's disease. Electroencephalogr. Clin. Neurophysiol. 74, 378-384.

Buchwald, J.S., Rubinstein, E.H., Schwafel, J., Strandburg, R.J., 1991. Midlatency auditory evoked responses: differential effects of a cholinergic agonist and antagonist. Electroencephalogr. Clin. Neurophysiol. 80, 303-309.

Bymaster, F.P., McKinzie, D.L., Felder, C.C., Wess, J., 2003. Use of M1-M5 muscarinic receptor knockout mice as novel tools to delineate the physiological roles of the muscarinic cholinergic system. Neurochem. Res. 28, 437-442.

Cadenhead, K.S., Light, G.A., Geyer, M.A., Braff, D.L., 2000. Sensory gating deficits assessed by the P50 event-related potential in subjects with schizotypal personality disorder. Am. J. Psychiatry 157, 55-59.

Campbell, K.A., Kalmbacher, C.E., Specht, C.D., Gregg, T.R., 1995. Dependence of rat vertex auditory evoked potentials on central muscarinic receptor activation. Brain Res. 702, 110-116.

Cancelli, I., Cadore, I.P., Merlino, G., Valentinis, L., Moratti, U., Bergonzi, P., Gigli, G.L., Valente, M., 2006. Sensory gating deficit assessed by $\mathrm{P} 50 / \mathrm{Pb}$ middle latency event related 
potential in Alzheimer's disease. J. Clin. Neurophysiol. 23, 421-425.

Caulfield, M.P., 1993. Muscarinic receptors-characterization, coupling and function. Pharmacol. Ther. 58, 319-379.

de Bruin, N.M.W.J., Ellenbroek, B.A., Van Schaijk, W.J., Cools, A.R., Coenen, A.M.L., Van Luijtelaar, E.L.J.M., 2001. Sensory gating of auditory evoked potentials in rats: effects of repetitive stimulation and the interstimulus interval. Biol. Psychol. 55, 195-213.

De Wilde, O.M., Bour, L.J., Dingemans, P.M., Koelman, J.H.T.M., Linszen, D.H., 2007. Failure to find P50 suppression deficits in young first-episode patients with schizophrenia and clinically unaffected siblings. Schizophr. Bull. 33, 1319-1323.

Dudar, J.D., Wishaw, I.Q., Szerb, J.C., 1979. Release of acetylcholine from the hippocampus of freely moving rats during sensory stimulation and running. Neuropsychopharmacology $18,673-678$.

Fein, G., Biggins, C., Van Dyke, C., 1994. The auditory P50 response is normal in Alzheimer's disease when measured via a paired click paradigm. Electroen. Clin. Neuro 92, 536-545.

Golob, E.J., Johnson, J.K., Starr, A., 2001. Auditory event-related potentials during target detection are abnormal in mild cognitive impairment. Clin. Neurophysiol. 113, 151-161.

Irimajiri, R., Golob, E.J., Starr, A., 2005. Auditory brain-stem, middle- and long-latency evoked potentials in mild cognitive impairment. Clin. Neurophysiol. 116, 1918-1929.

Jann, M.W., Shirley, K.L., Small, G.W., 2002. Clinical pharmacokinetics and pharmacodynamics of cholinesterase inhibitors. Clin. Pharmacokinet. 41, 719-739.

Jessen, F., Kucharski, C., Fries, T., Papassotiropoulos, A., Hoenig, K., Maier, W., Heun, R., 2001. Sensory gating deficit expressed by a disturbed suppression of the P50 event-related potential in patients with Alzheimer's disease. Am. J Psychiatry 158, 1319-1321.

Jin, Y., Bunney Jr., W.E., Sandman, C.A., Patterson, J.V., Fleming, K., Moenter, J.R., Kalali, A.H., Hetrick, W.P., Potkin, S.G., 1998. Is P50 suppression a measure of sensory gating in schizophrenia? Biol. Psychiatry 43, 873-878.

Jin, Y., Potkin, S.G., Patterson, J.V., Sandman, C.A., Hetrick, W.P., Bunney Jr., W.E., 1997. Effects of P50 temporal variability on sensory gating in schizophrenia. Psychiatry Res. 70, 71-81.

Katayama, S., Ishizaki, F., Yamamura, Y., Khoriyama, T., Kito, S., 1990. Effects of anticholinergic antiparkinsonian drugs on binding of muscarinic receptor subtypes in rat brain. Res. Commun. Chem. Pathol. Pharmocol. 69, 261-270.

Kathmann, N., Engel, R.R., 1990. Sensory gating in normals and schizophrenics: a failure to find strong P50 suppression in normals. Biol. Psychiatry 27, 1216-1226.

Klinkenberg, I., Blokland, A., 2010. The validity of scopolamine as a pharmacological model for cognitive impairment: a review of animal behavioral studies. Neurosci. Biobehav. Res. 34, 1307-1350.

Klinkenberg, I., Blokland, A., 2011. A comparison of scopolamine and biperiden as a rodent model for cholinergic cognitive impairment. Psychopharmacology 215, 549-566.

Krause, M., Hoffmann, W.E., Hajos, M., 2003. Auditory sensory gating in hippocampus and reticular thalamic neurons in anesthetized rats. Biol. Psychiatry 53, 244-253.

Lamberti, J.S., Schwarzkopf, S.B., Boutros, N., Crilly, J.F., Martin, R., 1993. Within-session changes in sensory gating assessed by P50 evoked potentials in normal subjects. Prog. Neuropsychopharmacol. Biol. Psychiatry 17, 781-791.

Legault, G., Smith, C.T., Beninger, R.J., 2004. Scopolamine during the paradoxical sleep window impairs radial arm maze learning in rats. Pharmacol. Biochem. Behav. 79, 715-721.

Levey, A.I., Edmunds, S.M., Koliatsos, V., Wiley, R.G., Heilman, C.J., 1995. Expression of $\mathrm{m} 1-\mathrm{m} 4$ muscarinic acetylcholine receptor proteins in rat hippocampus and regulation by cholinergic innervation. J. Neurosci. 15, 4077-4092.
Luntz-Leybman, V., Bickford, P.C., Freedman, R., 1992. Cholinergic gating of response to auditory stimuli in rat hippocampus. Brain Res. 587, 130-136.

Mesulam, M.M., Mufson, E.J., Wainer, B.H., Levey, A.I., 1983. Central cholinergic pathways in the rat: an overview based on an alternative nomenclature (ch1-ch6). Neuroscience 10, 1185-1201.

Miyazato, H., Skinner, R.D., Garcia-Rill, E., 1999. Sensory gating of the P13 midlatency auditory evoked potential and the startle response in the rat. Brain Res. 822, 60-71.

Miyazato, H., Skinner, R.D., Reese, N.B., Boop, F.A., Garcia-Rill, E., 1995. A middle-latency auditory-evoked potential in the rat. Brain Res. Bull. 37, 247-255.

Miyazato, H., Skinner, R.D., Reese, N.B., Mukawa, J., Garcia-Rill, E., 1996. Midlatency auditory evoked potentials and the startle response in the rat. Neuroscience 75, 289-300.

Nagamoto, H.T., Adler, L.E., Hea, R.A., Griffith, J.M., McRae, K.A., Freedman, R., 1996. Gating of auditory P50 in schizophrenics: unique effects of clozapine. Biol. Psychiatry 40, 181-188.

Nagamoto, H.T., Adler, L.E., Waldo, M.C., Freedman, R., 1989. Sensory gating in schizophrenics and normal controls: effects of changing stimulation interval. Biol. Psychiatry 25, 549-561.

Olincy, A., Braff, D.L., Adler, L.E., Cadenhead, K.S., Calkins, M.E., Dobie, D.J., Green, M.F., Greenwood, T.A., Gur, R.E., Gur, R.C., Light, G.A., Mintz, J., Nuechterlein, K.H., Radant, A.D., Schork, N.J., Seidman, L.J., Siever, L.J., Silverman, J.M., Stone, W.S., Swerdlow, N.R., Tsuang, D.W., Tsuang, M.T., Turetsky, B.I., Wagner, B.D., Freedman, R., 2010. Inhibition of the P50 cerebral evoked response to repeated auditory stimuli: results from the consortium on genetics of schizophrenia. Schizophr. Res. 119, 175-182.

Oranje, B., Geyer, M.A., Bocker, K.B.E., Kenemans, J.L., Verbaten, M.N., 2006. Prepulse inhibition and P50 suppression: commonalities and dissociations. Psychiat. Res. 143, 147-158.

Patterson, J.V., Jin, Y., Gierczak, M., Hetrick, W.P., Potkin, S., Bunney Jr., W.E., Sandman, C.A., 2000. Effects of temporal variability on P50 and the gating ratio in schizophrenia: a frequency domain adaptive filter single-trial analysis. Arch. Gen. Psychiatry 57, 57-64.

Pekkonen, E., Jaaskelainen, I.P., Kaakkola, S., Ahveninen, J., 2005. Cholinergic modulation of preattentive auditory processing in aging. Neurolmage 27, 387-392.

Potier, B., Lamour, Y., Dutar, P., 1993. Age-related alterations in the properties of hippocampal pyramidal neurons among rat strains. Neurobiol. Aging 14, 17-25.

Radek, R.J., Miner, H.M., Bratcher, N.A., Decker, M.W., Gopalakrishnan, M., Bitner, R.S., 2006. Alpha4beta2 nicotinic receptor stimulation contributes to the effects of nicotine in the DBA/2 mouse model of sensory gating. Psychopharmacology 187, 47-55.

Sambeth, A., Riedel, W., Smits, L., Blokland, A., 2007. Cholinergic drugs affect novel object recognition in rats: relation with hippocampal EEG? Eur. J. Pharmacol. 572, 151-159.

Simons, C.J.P., Sambeth, A., Krabbendam, L., Pfeifer, S., Van Os, J., Riedel, W.J., 2011. Auditory P300 and N100 components as intermediate phenotypes for psychotic disorder: familial liability and reliability. Clin. Neurophysiol. 122, 1984-1990.

Stevens, K.E., Kem, W.R., Mahnir, V.M., Freedman, R., 1998. Selective alpha7-nicotinic agonists normalize inhibition of auditory response in DBA mice. Psychopharmacology 136, 320-327.

Stevens, K.E., Wear, K.D., 1997. Normalizing effects of nicotine and a novel nicotinic agonist on hippocampal auditory gating in two animal models. Pharmacol. Biochem. Behav. 57, 869-874.

Teneud, L., Miyazato, H., Skinner, R.D., Garcia-Rill, E., 2000. Cholinergic modulation of the sleep state-dependent P13 midlatency auditory evoked potential in the rat. Brain Res. 884, 196-200.

Thomas, C., Vom Berg, I., Rupp, A., Seidl, U., Schroder, J., RoeschEly, D., Kreisel, S.H., Mundt, C., Weisbrod, M., 2010. P50 gating 
deficit in Alzheimer dementia correlates to frontal neuropsychological function. Neurobiol. Aging 31, 416-424.

Wildeboer, K.M., Stevens, K.E., 2008. Stimulation of the alpha4beta2 nicotinic receptor by 5 -I A-85380 improves auditory gating in DBA/2 mice. Brain Res. 1224, 29-36.

Woolf, N.J., Butcher, L.L., 1986. Cholinergic systems in the rat brain: III. Projections from the pontomesencephalic tegmentum to the thalamus, tectum, basal ganglia, and basal forebrain. Brain Res. Bull. 16, 603-637.
Woolf, N.J., Eckenstein, F., Butcher, L.L., 1984. Cholinergic systems in the rat brain: I. projections to the limbic telencephalon. Brain Res. Bull. 13, 751-784.

Yokogawa, K., Nakashima, E., Ishizaki, J., Hasegawa, M., Kido, H., Ichimura, F., 1992. Brain regional pharmacokinetics of biperiden in rats. Biopharm. Drug Dispos. 13, 131-140.

Zouridakis, G., Boutros, N.N., 1992. Stimulus parameter effects on the P50 evoked response. Biol. Psychiatry 32, 839-841. 